\title{
ФИЗИЧЕСКОЕ И МАТЕМАТИЧЕСКОЕ МОДЕЛИРОВАНИЕ ВАЛКОВОЙ РАЗЛИВКИ СТАЛЬНОЙ ПОЛОСЫ
}

\author{
А.В. Ноговицын, И.Р. Баранов
}

Физико-технологический институт металлов и сплавов НАН Украины, г. Киев, Украина

Исследовано влияние условий разливки (радиус валков, толщина получаемого листа, уровень и температура расплава в межвалковом зазоре) на физико-технологические параметры процесса. Рассчитаны максимально допустимые скоростные режимы получения металлических полос различной толщины в валкахкристаллизаторах разного диаметра. Выполнены физическое и вычислительное исследования гидродинамики расплава в межвалковом зазоре. Получены зависимости предела текучести для углеродистых и легированных сталей в малоисследованном интервале температур - выше температуры солидус.

Ключевые слова: двухвалковое литье, межвалковый зазор, валок-кристаллизатор, расплав, математическая модель, механические свойства.

Введение. Валковая разливка-прокатка является одним из наиболее перспективных и эффективных процессов производства стального листа. К преимуществам этой технологии относятся компактность агрегата и экономия до 80...89\% энергоресурсов за счет отсутствия промежуточного подогрева материала и минимизации числа технологических операций. Однако, несмотря на попытки внедрения в производство технологии двухвалковой разливки на сегодня не удается в полной мере 
решить задачи устойчивого промышленного процесса получения качественного стального листа. Это связано с недостаточной изученностью закономерностей формирования непрерывно литой полосы, сложностью управления гидродинамическими, температурными, кинематическими параметрами процесса литьяпрокатки.

Цель paботы. Изучить закономерности процессов тепломассопереноса, затвердевания и деформации металлической ленты при литье-прокатке, которые позволят выбирать оптимальные технологические режимы.

Актуальныци уровень техники и исследований. Интенсивные работы по развитию процесса производства тонкой стальной полосы на двухвалковых литейно-прокатных агрегатах проводятся в Великобритании (British Steel, Corus), Японии (Nippon Steel Corp., Kawasaki Works, Nippon Metals, Pacific Metals, Sumimoto Metals), Канаде (Project Bessemer), Китае (Baoshan Iron and Steel Co.), Kopee (Posco)). Наибольшая промышленная эффективность валковой разливки достигнута в США на агрегатах Castrip фирмы Nucor [2]. Исследования валковой разливки металлов проводились и в Украине. Одесским НИИСЛ в 1955 г. были разработаны способ и установка для непрерывного литья тонких листов из чугуна в двухвалковые кристаллизаторы с подводом металла сверху [3]. В Физикотехнологическом институте металлов и сплавов (ФТИМС) НАН Украины была предложена и опробована конструкция агрегата для литья ленты [4]. В совместных работе Национальной металлургической академии Украины и Ганноверского Университета им. Лейбница описаны особенности конструкции и основные технические характеристики экспериментальной машины валковой разливки-прокатки собственной разработки $[5]$.

Постановка задачи. В работе решались следующие научные задачи: провести экспериментальные и теоретические исследования гидродинамики расплава в межвалковом зазоре 
(MB3) при различных его параметрах; исследовать процесс образования затвердевшей корочки на валках-кристаллизаторах; изучить реологические свойства затвердевающего металла (стали) в диапазоне температур «солидус-ликвидус»; исследовать влияние конструктивных (диаметр валков) и технологических параметров валковой разливки (высота ванны жидкого металла, температура металла, степень обжатия и др.) на протяженность зон кристаллизации и деформации, на скорость разливки стальных полос различной толщины; оценить влияние способа подачи расплава в валки на распределение температуры и затвердевание полосы по ее ширине на выходе из валков.

\section{Экспериментальное исследование течения модельной}

\section{среды.}

Физическое моделирование проводилось на двухвалковой лабораторной установке. Для устойчивой фиксации жидкости в межвалковом пространстве использовалась прозрачная призма, изготовленная из оргстекла (рис.1). Стенки призмы повторяли геометрию окружности бочки валков. В качестве моделирующей жидкости использовалась вода. Визуализацию потоков осуществляли при помощи добавления в воду полистироловых шариков (трассеров) диаметром 0,8..1,0 мм, имеющих нулевую плавучесть. Направление и скорости потоков фиксировали с помощью веб-камеры. Запись гидродинамической картины велась на компьютер. Область наблюдения в межвалковом пространстве модели прозрачного бункера получали обтюрируемым пучком света.

Количественные значения скоростей потоков жидкости определяли посредством расчета отношения измеренных на экране монитора длин треков ко времени экспозиции с учетом коэффициента масштабирования. $\mathrm{B}$ процессе выполнения исследований было проведено несколько экспериментов с использованием воды с различной концентрацией трассеров. Наилучший результат дало использование жидкости с плотностью 
шариков 200 шт/литр. После получения изображения треков, было построено поле движения трассеров (рис.2).

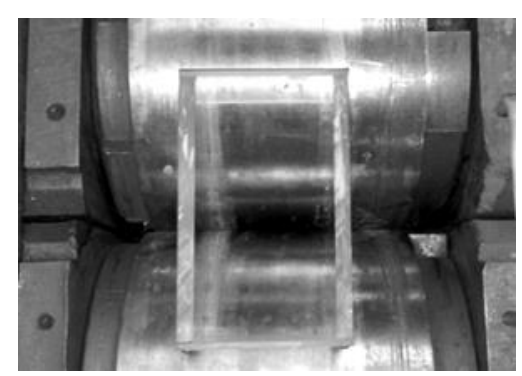

$a$

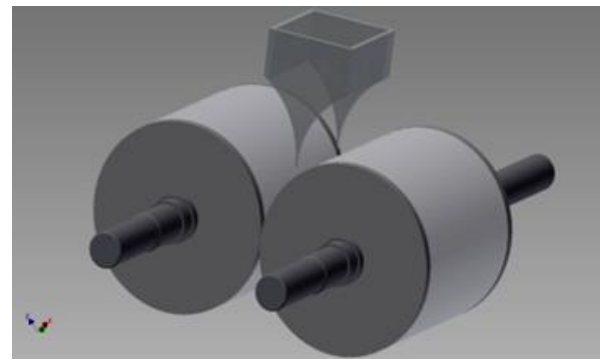

$\sigma$

Рис. 1. Призма, моделирующая устойчивое удержание жидкости в межвалковом зазоре (a) вид сверху (б) аксонометрическая модель

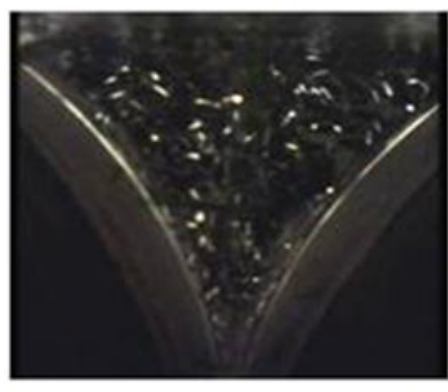

$a$

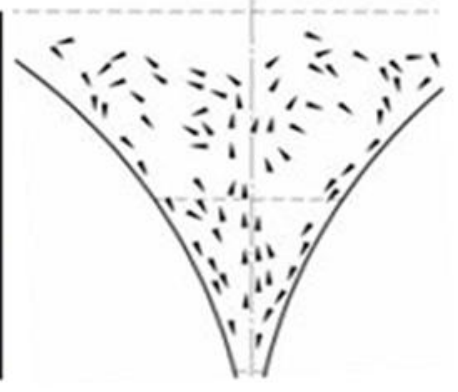

$\sigma$

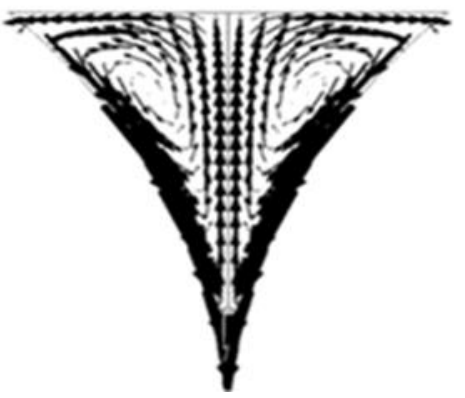

C

Рис. 2. Поле движения трассеров: $a$ - фотоснимок треков частичек;

$\sigma$ - полученное поле движения; $c$ - компьютерная модель

На основе зафиксированных параметров движения трассеров в физической модели, построено векторное поле скоростей, на котором можно четко проследить образование двух зон циркуляции. Наибольшая скорость движения потока жидкости находится вблизи поверхности валков, которые нагнетают жидкость в межвалковый зазор. Обратный поток, возникающий в точке встречи поверхностных потоков и проходящий вдоль центральной оси межвалкового пространства, имеет значительно меньшую скорость. 
Результаты физического моделирования сопоставляли с результатами компьютерного моделирования поля скоростей жидкости в межвалковом зазоре двухвалкового кристаллизатора, выполненых совместно с учеными Института электродинамики НАН Украины с использованием пакета программ Comsol $[6,7]$. Результаты численного расчета и эксперимента хорошо согласуются между собой, что дало возможность создания надежного математического аппарата для исследования течения металла в процессе валковой разливки и более глубокого понимания процессов, протекающих в межвалковом пространстве.

Компьютерное исследование течения расплав. Для моделирования турбулентного течения жидкости в активной зоне установки в качестве основной модели используется $k-\varepsilon$ модель турбулентности. Другой упрощенный расчет турбулентного течения проводится путем задания постоянного во всей области эффективного значения турбулентной вязкости, вычисляемого с помощью формулы Прандтля . Показано, что эффективная вязкость жидкости должна превышать молекулярную вязкость (равную для воды $10^{-3}$ Па·с) более, чем в 100 раз [7].

\section{Оценка влияния геометрических параметров зоны} разливки на параметры течения. Проведены расчеты для трех вариантов разливки в валки-кристаллизаторы диаметром 500 мм - при высоте налива расплавленного металла $l=45,90,135$ мм (угол мениска 10, 20, 30) [6]. Анализ расчетных данных (рис. 3) показывает на значительную неравномерность распределения скоростей течения в поперечных сечениях межвалкового зазора. 

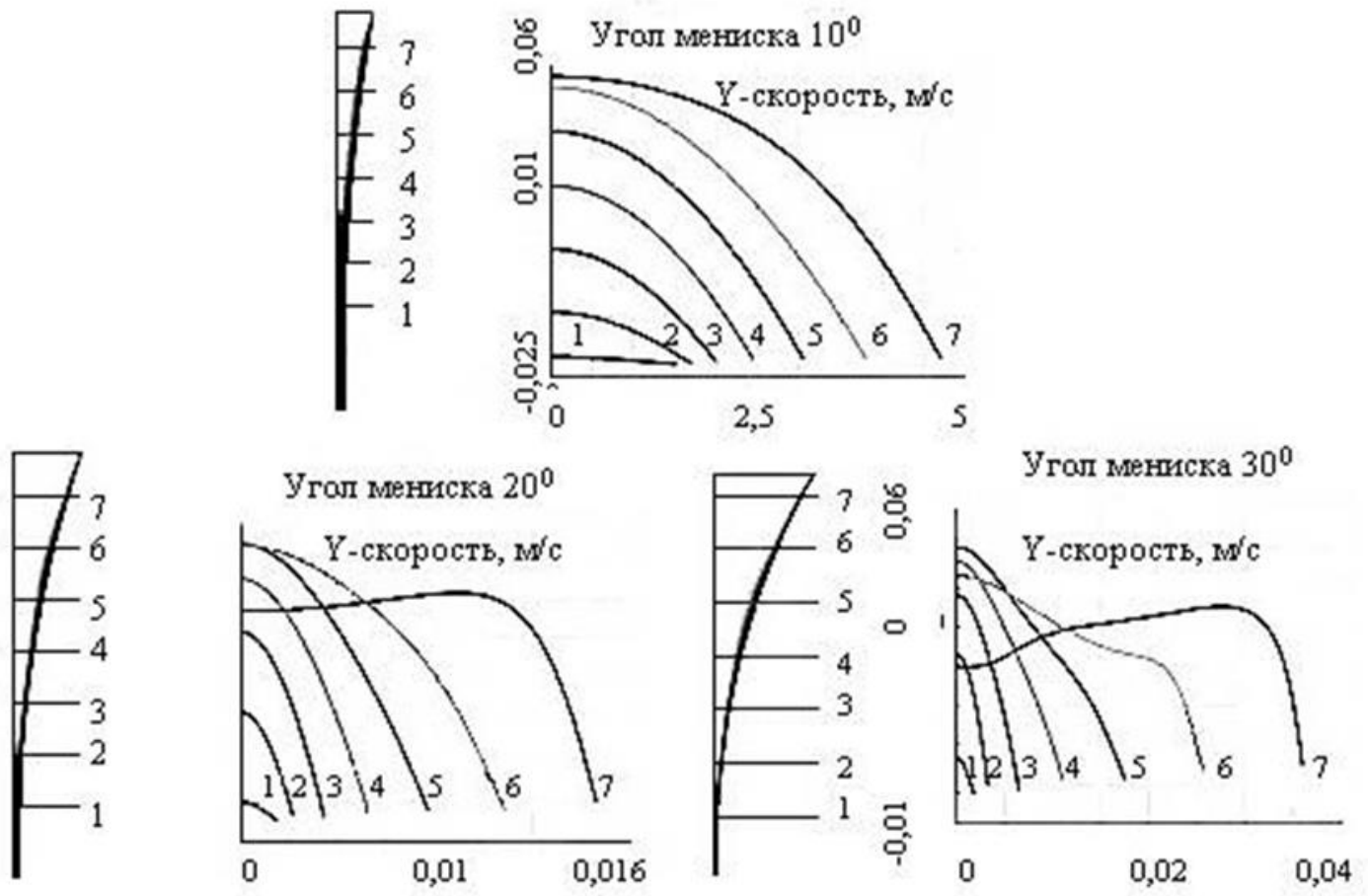

Рис. 3. Изменение $y$ - составляющей скорости вдоль семи показанных слева поперечных сечений $1 / 2$ межвалкового канала для трех вариантов высоты мениска

В слоях металла, прилегающих к валку, наблюдаются значительные градиенты продольной скорости течения. Металл центральной части верхней половины MB3 отстает от окружной скорости валка и находится в состоянии, близком к застойному. С увеличением высоты налива до 90 мм (угла $\alpha$ свыше 20) на поверхности мениска появляется тенденция к попятному движению метала из межвалкового зазора, что может вызывать бурление метала. При высоте налива 135 мм $\left(\alpha=30^{\circ}\right)$ скорость попятного движения метала имеет величину, соответствующую $20 \%$ скорости вращения валка-кристаллизатора, т.е. 170 мм/сек. С увеличением диаметра валков-кристаллизаторов $\left(\begin{array}{lll}1500 & \text { мм})\end{array}\right.$ скорости попятного течения существенно возрастают и могут достигать весьма больших значений (до 520 мм/сек). Такое интенсивное обратное течение расплава на поверхности мениска MB3 может вызывать выбросы расплава из межвалкового зазора. 
Затвердевание металла. Решающей характеристикой процесса формирования полосы в валковом кристаллизаторе является положение точки смыкания затвердевших корочек относительно плоскости оси валков. Если точка смыкания значительно выше линии осей валков («бесслитковая прокатка»), то в результате деформации затвердевшего металла усилие на валки возрастает. С одной стороны это вызывает необходимость увеличивать мощность привода и прочность конструкции кристаллизатора, с другой, может привести к появлению трещин вследствие эффекта прокатки. Наоборот, если точка смыкания фронтов кристаллизации находится ниже линии осей валков («жидкая прокатка»), то из валков выходит полоса с жидкой сердцевиной.

Сложность экспериментального установления границы между двумя характерными областями зоны кристаллизациидеформации заставляет обращаться к математическому моделированию. Толщину корочки в работе определяли двумя методами: по формуле «квадратного корня» и путем расчета положения линии солидуса на рассчитанном поле температур метала в межвалковом зазоре.

Для расчета толщины методом «квадратного корня» необходимо знать значения коэффициента кристаллизации для разливаемого металла. В литературе они, как правило, приводятся для случая затвердевания металлов в слитках, когда между затвердевшей корочкой и охлаждающей стенкой образуется газовый (воздушный) слой, задерживающий теплопередачу. Опубликованных работ по экспериментальному исследованию параметров процесса затвердевания расплавов при валковой разливке крайне мало. Для определения коэффициента скорости кристаллизации $k$ при валковой разливке-прокатке стальной полосы воспользовались результатами исследований T. Мизогучи и К. Миязава [8]. Суть их экспериментов заключалась в исследовании структурообразования стальной полосы из нержавеющей стали в зависимости от времени 
контакта металла с металлической подложкой. Мы установили, что расчеты наиболее точно приближены к экспериментальным значениям толщины затвердевшей корочки при $k=4,2 \mathrm{Mм} / \mathrm{ce \kappa}^{0,5}$.

В основу второго способа расчета затвердевшей корочки положено решение уравнения нестационарной теплопроводности методом конечных разностей [9]. В результате расчета распределения температуры расплава определяется положение изотерм «ликвидус» $\left(\mathrm{T}_{\mathrm{L}}\right)$ и «солидус» $\left(\mathrm{T}_{\mathrm{S}}\right)$. За толщину корочки принимают расстояние от образующей валка до линии солидус. Однако достоверность таких расчетов существенно зависит от значений многих констант, входящих в уравнения теплопроводности (коэффициенты теплопроводности металла в жидком и твердом состояниях, коэффициент теплопередачи от металла к валку, теплота фазового превращения). Кроме того, значения температур «ликвидус» и «солидус» зависят от интенсивности теплоотвода от затвердевающего металла [10].

Реология стали при температурах валковой разливки. Данные о свойствах стали при температурах вблизи температуры солидуса и выше (в двухфазной твердо-жидкой зоне) исследованы крайне мало. В ФТИМС НАН Украины под руководством Ю.А.Скока исследованы механические свойства низкоуглеродистых, углеродистых, низколегированных, среднелегированных и высоколегированных сталей (таблица 1) при высоких температурах, приближенных до температуры плавления [11].

Таблица 1. - Химический состав сталей, исследованных в работе [11]

\begin{tabular}{|c|c|c|c|c|c|}
\hline \multirow{2}{*}{ № } & \multirow{2}{*}{$\begin{array}{l}\text { Марка } \\
\text { сталі }\end{array}$} & \multicolumn{4}{|c|}{ Хімічний склад, \% } \\
\hline & & $\mathrm{C}$ & $\mathrm{Si}$ & $\mathrm{Mn}$ & $\mathrm{Ni}$ \\
\hline 0 & Армко & 0,02 & 0,02 & 0,13 & 0,01 \\
\hline 1 & $17 Г С Л$ & 0,17 & 0,54 & 1,4 & 0,01 \\
\hline 2 & $20 \Gamma \mathrm{CH}$ & 0,21 & 0,78 & 1,15 & 0,58 \\
\hline 3 & 17Г2АФЛ & 0,18 & 0,46 & 1,56 & 0,01 \\
\hline
\end{tabular}




\begin{tabular}{|c|c|c|c|c|c|}
\hline \multicolumn{6}{|c|}{ Продолжение таблицы 1} \\
\hline 4 & 09Г2C & 0,085 & 0,64 & 1,45 & 0,01 \\
\hline 5 & $22 \mathrm{X} 3 \mathrm{M}$ & 0,22 & 0,28 & 1,45 & 0,01 \\
\hline 6 & 45ХНМФЛ & 0,46 & 0,29 & 0,66 & 0,96 \\
\hline 7 & 20Л & 0,17 & 0,36 & 0,54 & 0,01 \\
\hline 8 & 55Л & 0,55 & 0,35 & 0,5 & 0,01 \\
\hline$\overline{9}$ & ШХ15 & 1,03 & 0,3 & 0,31 & 0,01 \\
\hline 10 & $12 \times H 3 A$ & 0,13 & 0,34 & 0,57 & 2,91 \\
\hline 11 & 10ГН2МФА & 0,1 & 0,28 & 0,86 & 2,16 \\
\hline 12 & 15Х1М1ФЛ & 0,16 & 0,32 & 0,78 & 0,01 \\
\hline 13 & 9Х2МФ & 0,9 & 0,32 & 0,3 & 0,01 \\
\hline 14 & Х28Л & 0,05 & 0,72 & 0,63 & 0,01 \\
\hline 15 & 09X16H4 & 0,1 & 0,55 & 0,46 & 4,23 \\
\hline 16 & Х18Н10ТЛ & 0,07 & 0,86 & 1,3 & 10,23 \\
\hline
\end{tabular}

Нами для построения зависимости предела текучести $\left(\sigma_{\mathrm{T}}^{\prime}\right)$ стали в интервале температур $\mathrm{T}_{\mathrm{S}} \leq T \leq \mathrm{T}_{\mathrm{L}}$ была введена безразмерная температура $\overline{\mathrm{T}}=\frac{\mathrm{T}_{\mathrm{L}}-\mathrm{T}}{\mathrm{T}_{\mathrm{L}}-\mathrm{T}_{\mathrm{S}}}$, которая принимает значения от 1 до 0 . По известной гипотезе [12] значение $\bar{T}$ соответствует доле твердой фазы в стали при заданной температуре металла.

Анализ экспериментальных данных показал (рис. 4), что в качестве зависимости предела текучести от $\bar{T}$ можно применить степенную функцию: $\sigma_{T}^{\prime}=\sigma\left(T_{S}\right) \cdot \overline{T^{n}}$, где $\sigma\left(T_{S}\right)$ - сопротивление деформации при температуре «солидус», $n=4$. Абсолютная погрешность формулы составляет 1,09 H/Mм² . 


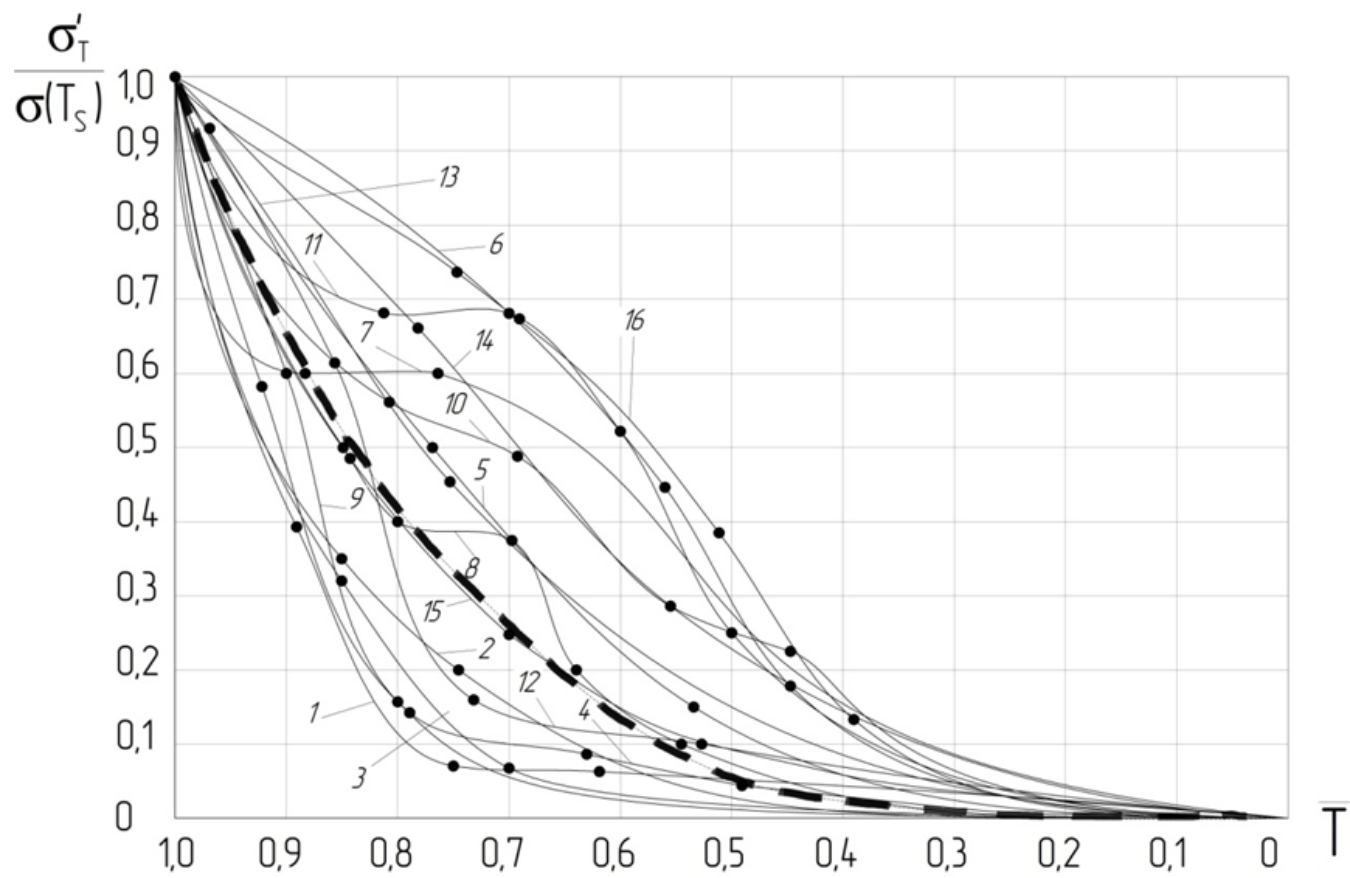

Рис. 4. Зависимость значения $\sigma_{\mathrm{T}}{ }^{\prime} / \sigma\left(\mathrm{T}_{\mathrm{s}}\right)$ от температуры $\overline{\mathrm{T}}$ :

- - эксперимент; - - - расчетные данные

Цифры у кривых соответствуют номеру стали в таблице 1.

Влияние толщины и обжатия полосы, диаметра валков-кристаллизаторов, уровня наполнения расплава на скорость разливки.

Ключевым фактором для достоверного расчета скорости разливки является правильное определение положения смыкания затвердевших на валках-кристаллизаторах корочек разливаемого металла. Применение не достоверных методик приводит к ошибкам при проектировании оборудования. Нами рассчитаны скорости разливки стальных полос толщиной от 1 до 5 мм с обжатием (15\%) и без обжатия в валках различного диаметра. Из расчетов следует, что осуществление валковой разливки полосы с обжатием приводит к заметному снижению скорости розливки-прокатки. Например, для стальной полосы толщиной 2 мм при обжатии 15\% скорость разливки снижается в 3 раза (с 164 до 52 м/мин) по сравнению с разливкой без обжатия. 
На рис. 5 приведены скорости разливки стальных полос различной толщины $\left(h_{n}\right)$ в валках-кристаллизаторах радиусом $\mathrm{R}=500$ мм при изменении угла контакта металла с валком $\alpha=10,20$ и $30^{\circ}$ без деформации и с деформацией 15\%. Из приведенных данных следует, что увеличение угла контакта металла с валком (уровня заливки металла) приводит к существенному росту скорости разливки. Расчетные скорости разливки для стальных полос количественно близки к достигнутым на установке Castrip компании Nucor. Сопоставив применяемую скорость разливки 80 м/мин для получения полосы толщиной 1,6 мм в валках диаметром 500 мм, можно сделать вывод, что разливка-прокатка осуществляется с обжатием затвердевшего металла близким к $15 \%$.

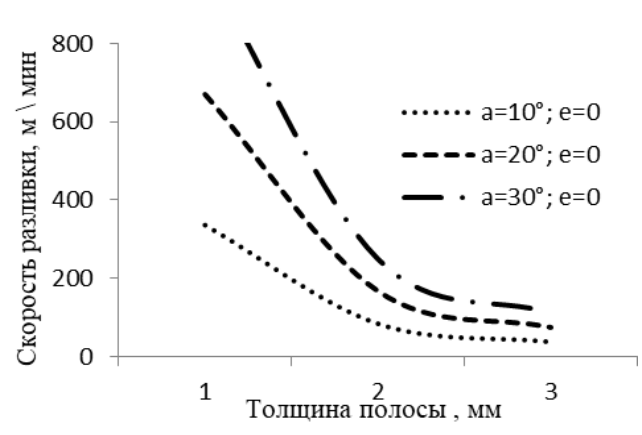

$a$

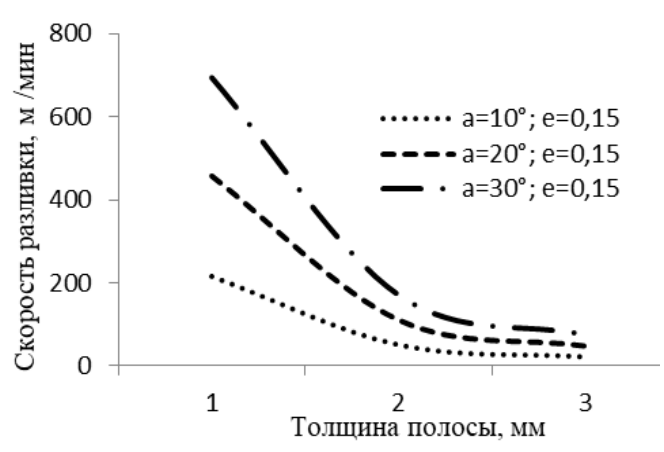

б

Рис. 5. Зависимость расчетной скорости разливки-прокатки стальных полос от толщины, угла зоны кристаллизациидеформации $\alpha$, без обжатия ( $a$ ), и с обжатием 15\% (б) (радиус валков-кристаллизаторов 500мм)

Расчеты показывают, что для обеспечения постоянного положения точки смыкания корочек затвердевшего металла скорость разливки должна регулироваться пропорционально изменению высоты налива. Увеличение высоты налива при постоянной (нерегулируемой) скорости приводит к увеличению степени деформации, которая может достигать критической величины, приводящей к появлению в полосе трещин. Важным фактором стабильной технологии валковой разливки является обеспечение постоянной температуры металла, подаваемого в 
валки-кристаллизаторы. Показано, что изменение температуры металла на $10^{\circ} \mathrm{C}$ приводит к изменению толщины корочки стали на 0,05 мм, что приводит к изменению обжатия на $3 \%$ (абс.) при постоянной скорости разливки, что в свою очередь может приводить к продольной разнотолщинности полосы, а также может содействовать появлению трещин.

Немаловажную роль в валковой разливке играет способ подачи расплава в валки-кристаллизаторы. Проведенное исследование [13] показало, что увеличение длины щелевого питателя от 25 до $100 \%$ длины валка-кристаллизатора обеспечивает более равномерное распределение температуры в межвалковом канале, а перепад температур по ширине полосы на выходе из валков уменьшается с $80^{\circ} \mathrm{C}$ до $10^{\circ} \mathrm{C}$.

Заключение. Установленные закономерности показали, что необходимыми условиями для стабильного процесса валковой разливки являются постоянство температуры и расхода подаваемого в валки-кристаллизаторы металла, равномерное его распределение по длине межвалкового зазора. Решение этой задачи возможно путем применения МГД-оборудования. В ФТИМС НАН Украины разработана концепция и принципиальная схема процесса валковой разливки стали, главным признаком которой является использование магнитодинамического промежуточного ковша (МД-ПК), созданного на базе магнитодинамического миксера-дозатора жидкой стали [14]. Применительно к процессам валковой разливки, электромагнитные поля и соответствующие устройства следует использовать на следующих стадиях процесса: 1) в промежуточном ковше - для поддержания заданной температуры расплава непосредственно перед разливкой; 2) на выходе из промежуточного ковша - для управления гидродинамическим режимом поступления расплава в валковый кристаллизатор. 


\section{Литература}

1. Матвеев Б.Н. Технология валкового литья-прокатки тон-ких полос. Результаты исследований и промышленное освоение. - М. : ОАО «Черметинформация», 2008. - 59 с.

2. Шалимов Ал. Г. Двухвалковые литейно-прокатные агрегаты для производства тонких горячекатаных стальных полос. Ч.ІІ // Электрометаллургия. 2014. №2. С.12-16.

3. Степанов А.Н., Ю.В. Зильберг Ю.В., Неуструев А.А. Производство листа из расплава. : Учебник.- М. : Металлургия, 1978. - 160 с.

4. Найдек В.Л., Осіпов В.П., Узієнко Б.О., Перелома В.О., Дубровін Е.В., Казачков Є.О., Майко О.І. Спосіб виготовлення металевої стрічки.: Патент 45433 Україна, МПК7 В22В 11/06, В220 11/11 // Бюл. «Промислова власність», 2002, №4.

5. Гридин А. Ю., Шапер М., Данченко В. Н. Получение полос из высокопрочных алюминиевых сплавов валковой разливкой-прокаткой // Обработка металлов давлением. 2011. № 3 (28). С. 184-194.

6. Ноговицын А.В., Подольцев А.Д., Кучерявая И.Н., Ломко А.Н. Компьютерное моделирование течения расплава в двухвалковом кристаллизаторе //Процессы литья. 2014. №6. С.11-17.

7. Ноговицын А.В., Подольцев А.Д., Кучерявая И.Н. Численное моделирование турбулентного течения расплава в двухвалковом кристаллизаторе с щелевым питателем// Процессы литья. 2015. №2. C.33-39.

8. Mizoguchi T., Miyazawa K. Formation of solidification structure in a twin-roll rapid solidification process // Advanced Materials and Process. 1990. Vol. 1. Р. 93-98.

9. Найдек В.Л., Тарасевич Н.И., Корниец И.В., Тарасевич И.Н.Оценка параметров валковой разливки металла при формировании тонкой полосы на базе компьютерного моделирования // Сталь. 2017, №7. С.6570.

10. Мартынов О.В, Дубовенко И.П., Семенцов А.Н., Ежов А.А., Дюдкин Д.А. Тепловые и диффузионные процессы при разливке стали и способы их регулирования// Сб.: Теплофизика стального слитка. Киев: ИПЛ АН УССР. 1980. С. 36-41.

11. Скок Ю.Я. Механические свойства стали при температурах вблизи солидуса // Препринт. Киев: Ин-т проблем литья АН Украины. 1983. $66 \mathrm{c}$.

12. Ольшанский В.М., Коваль Н.П., Сью Т.Я. Математическое 
моделирование процесса затвердевания непрерывных заготовок // Металлургическая теплотехника. 1999. №2. С. 188-191.

13. Ноговицын А.В., Подольцев А.Д., Кучерявая И.Н. Трехмерное моделирование гидродинамических процессов в двухвалковом кристаллизаторе при различных способах подачи метала// Праці IЕД НАНУ.2015.Вип. 40. С.95-102.

14. Дубоделов В.И., Погорский В.К., Горюк М.С. Магнитодинамическое оборудование для перегрева и разливки чугуна и стали// Оборудование и инструмент для профессионалов. 2013. № 1. С. 134-137. 